\title{
Educação em tempo integral: contribuições oriundas das pesquisas de pós-graduação
}

Elba Siqueira de Sá Barretto* Katia Regina de Sá **

* (Faculdade de Educação da Universidade de São Paulo e Fundação Carlos Chagas, São Paulo, SP)

** (Faculdade de Educação da Universidade de São Paulo, São Paulo, SP, e Instituto Federal de Minas Gerais, Betim, MG)
Resumo: A proposta deste artigo é apresentar o panorama das pesquisas oriundas da pós-graduação stricto sensu que investigam a educação em tempo integral (ETI) e seu currículo. A análise de oito pesquisas selecionadas na base de dados do Banco de Teses da Capes e da Biblioteca Digital Brasileira de Teses e Dissertações revelou que: a) o contexto da realização está distante do contexto da formulação, no que se refere às finalidades da ETI presentes nos documentos oficiais; b) a implantação apresentou problemas a serem superados, sendo que alguns deles se repetem em diferentes localidades; e c) ainda não há uma visão clara sobre o currículo da escola de tempo integral.

Palavras-chave: Educação. Tempo integral. Currículo. Plano Nacional de Educação. 
Nos últimos anos houve acelerada expansão na oferta de educação em tempo integral (ETI) no Brasil e o número de matrículas deve continuar crescendo nos próximos anos rumo à meta estabelecida no Plano Nacional de Educação (PNE), que prevê a oferta dessa jornada estendida para, no mínimo, 25\% dos alunos da educação básica da rede pública até o ano de 2024.

A ETI passou a ser oferecida em larga escala no Brasil há menos de uma década. As experiências anteriores não tiveram propagação e longevidade, tais como: a Escola Parque concebida por Anysio Teixeira, em Salvador, no ano de 1950 e em Brasília em 1960; na mesma época surgiram os Ginásios Vocacionais em São Paulo; posteriormente os Centros Integrados de Educação Pública (Cieps) no Rio de Janeiro, nas décadas de 1980 e 1990; o Programa de Formação Integral da Criança (Profic), entre os anos de 1986 e 1993 em São Paulo, e os Centros Integrados de Atenção à Criança (Ciacs) ${ }^{1}$ em 1991. Há uma agenda favorável à consolidação da ETI na atualidade, resultante do conjunto de ações governamentais, não governamentais e de demandas sociais. Contudo, é necessário atentar para a concepção de educação integral assumida pelas diferentes iniciativas e acompanhar o desenvolvimento dos programas, a fim de garantir o alcance de suas finalidades e o atendimento das necessidades dos alunos.

Apesar da existência de regulamentações e diretrizes, a ETI está em processo de construção e não há certeza sobre suas finalidades, sobre as experiências de aprendizagem que devem ser promovidas na ampliação do tempo de permanência dos alunos nas escolas e sobre os problemas recorrentes enfrentados na sua implantação. Para Cavaliere (2014), não há conceito ou prática firmados sobre o que seja educação integral escolar, portanto, é necessário formular/aperfeiçoar modelos de trabalho que articulem áreas disciplinares e temáticas, sendo inevitáveis discussões mais aprofundadas sobre currículo. A proposta deste artigo é apresentar o panorama das pesquisas oriundas da pós-graduação stricto sensu que investigam a ETI e seu currículo. Este estudo tenciona trazer à tona as contribuições dessas pesquisas, alertar sobre os principais problemas enfrentados pelas escolas durante a implantação dos programas e confrontar a realidade da ETI com a regulamentação que estruturou sua retomada. Ao ampliar e aprofundar os conhecimentos sobre a implantação da ETI pode-se avançar na compreensão dessa política pública, contribuindo para desvelar suas reais finalidades.

Os Ciacs, com proposta semelhante aos Cieps, foram esboçados no governo de Fernando Collor em 1991, com o apoio de Darcy Ribeiro e Leonel Brizola. A partir das mudanças promovidas na presidência de Itamar Franco, os Ciacs passaram a ser denominados Centros de Atenção Integral à Criança e ao Adolescente (Caics) (GOMES, 2010). 
A ETI é um dos itens das políticas públicas para a educação brasileira na Lei de Diretrizes e Bases da Educação Nacional (LDBEN) que determina que a jornada escolar no ensino fundamental deve ser progressivamente ampliada rumo à educação de tempo integral, e afirma que serão conjugados todos os esforços objetivando a progressão das redes escolares públicas urbanas de ensino fundamental para o regime de escolas de tempo integral (BRASIL, 1996).

Em conformidade com a LDBEN, o governo federal incluiu a ETI na pauta do PNE 2001-2011 e criou o Programa Mais Educação (PME), através de portaria normativa interministerial $\mathrm{n}-17$ de 2007, com o objetivo de fomentar a educação integral de crianças, adolescentes e jovens, por meio do apoio a atividades socioeducativas no contraturno escolar (BRASIL, 2007a). Nesse mesmo ano, a Lei no 11.494, que regulamenta o Fundo de Manutenção e Desenvolvimento da Educação Básica e de Valorização dos Profissionais de Educação (Fundeb), define que os recursos passam a ser diferenciados para a $\mathrm{ETI}^{2}$, o que significa que os sistemas estaduais e municipais que ampliarem a jornada escolar passarão a receber recursos extras (BRASIL, 2007b).

Em 2009 o PME publica os "Pressupostos para Projetos Pedagógicos de Educação Integral”, no caderno Rede de Saberes Mais Educação, contendo a apresentação do programa e as bases para a elaboração de propostas pedagógicas de educação integral por meio do diálogo entre saberes escolares e comunitários. Para o PME, as práticas realizadas além do horário escolar precisam estar sintonizadas com o currículo e os desafios acadêmicos, colaborando para a elaboração de um paradigma de educação integral que reúna diversas áreas, experiências e saberes, com condições de mútuas influências e negociações sucessivas. A concepção de educação integral adotada considera a ampliação das necessidades formativas do sujeito, contemplando as dimensões afetiva, ética, estética, social, cultural, política e cognitiva. 0 documento apresenta uma estrutura com sete macrocampos que dialogam diretamente com os programas de governo. São eles: a) acompanhamento pedagógico; b) meio ambiente; c) esporte e lazer; d) direitos humanos e cidadania; e) cultura e artes; f) inclusão digital e comunicação, e g) saúde, alimentação e prevenção. As escolas podem escolher três ou quatro macrocampos, respeitada a obrigatoriedade de escolha do macrocampo acompanhamento pedagógico, e, tomando-os como referências, deverá optar

Para mais esclarecimentos sobre financiamento da ETI, consultar MENEZES (2012). 
por quatro atividades para serem desenvolvidas com os alunos (BRASIL, 2009).

Em 2010 a ETI é contemplada em três documentos: o Decreto Presidencial no 7.083, as Diretrizes Curriculares Nacionais para o Ensino Fundamental de nove anos e o Plano Nacional de Educação para o decênio 2011-2020. O Decreto Presidencial no 7.083 estabelece que o PME tem por finalidade contribuir para a melhoria da aprendizagem por meio da ampliação do tempo de permanência de crianças, adolescentes e jovens matriculados em escola pública, mediante oferta de educação básica em tempo integral, com jornada igual ou superior a sete horas diárias (BRASIL, 2010a). As Diretrizes Curriculares Nacionais para o Ensino Fundamental de nove anos contemplam a ETI nos artigos 36 e 37, em que reafirmam o progressivo aumento da carga horária diária e anual, com vistas à maior qualificação do processo de ensino-aprendizagem, tendo como horizonte o atendimento escolar em período integral (BRASIL, 2010b). O Plano Nacional de Educação para o decênio 2011-2020 incorporou a ETI como uma de suas metas e propôs sua oferta em $50 \%$ das escolas públicas brasileiras.

A partir de então, houve um aumento considerável da oferta de ETI nas escolas públicas de educação básica no Brasil. Em 2011, a ETI atingia 7,5\% das matrículas e era oferecida em 26,1\% das escolas. Em 2014 esse percentual subiu para $15,7 \%$ das matrículas e $42 \%$ das escolas (TODOS PELA EDUCAÇÃO, 2015). O PNE, aprovado em 2014, mantém a meta de oferta da ETI em 50\% das escolas, para o decênio 2014-2024, e acrescenta que, além disso, deve atender pelo menos 25\% dos alunos da educação básica (BRASIL, 2014). Nele também são definidas estratégias para o alcance da meta que estão em conformidade com os pressupostos do PME, apesar de algumas mudanças em relação aos planos anteriores, o que abriu espaço para o crescimento de parcerias com organizações sociais de variadas nuances ${ }^{3}$.

\section{A PRODUÇÃO ACADÊMICA SOBRE ETI}

Com o propósito de conhecer o panorama das pesquisas sobre ETI que discutem questões referentes ao currículo, foi realizado um estudo exploratório, iniciado em maio de 2015, com um levantamento da produção da pós-graduação stricto sensu através de buscas na base de dados do Banco de Teses da Capes e da Biblioteca Digital Brasileira de Teses e Dissertações (BDTD), com

Cavaliere (2014) discute essas mudanças em seu artigo "Escola pública de tempo integral no Brasil: filantropia ou política de estado?". 
as palavras-chave "tempo integral" e "currículo". A busca inicial apontou 42 trabalhos. Entretanto, após uma triagem que utilizou como critério a inclusão das palavras-chave "tempo integral” e "currículo" pelo próprio autor em seu manuscrito, apenas oito trabalhos integraram a seleção. A busca realizada no Banco de Teses da Capes indicou duas dissertações, contudo, apenas os trabalhos defendidos nos anos de 2011 e 2012 estavam disponíveis para consulta, devido ao trabalho de manutenção do sistema para atualização das informações. A busca realizada no BDTD resultou em cinco dissertações e uma tese.

As oito pesquisas, publicadas no período compreendido entre 2009 e 2014, apresentaram análises sobre a escola ETI e seu currículo a partir de diferentes perspectivas, mas todas apontaram problemas a serem superados, sendo que alguns deles se repetem em diferentes localidades.

Cinco estudos realizaram pesquisas de campo no interior das escolas (RAMOS, 2011; BRANDÃO, 2009; MOREIRA, 2013; FIGUEIREDO, 2011; HENRIQUES, 2012). Dois estudos analisaram redes de ensino (SOARES, 2014; SILVA, 2011) e um estudo investigou a parceria entre uma escola de ensino fundamental e um centro social urbano (FONTANA, 2013). O Quadro 1 apresenta informações sobre os oito estudos selecionados.

Quadro 1 - Pesquisas de pós-graduação stricto sensu sobre ETI.

\begin{tabular}{|l|l|l|}
\hline \multicolumn{1}{|c|}{ Autor e Ano } & \multicolumn{1}{|c|}{ Título } & \multicolumn{1}{c|}{ Objetivo } \\
\hline BRANDÃO, 2009 & $\begin{array}{l}\text { Tempo e espaço no } \\
\text { currículo escolar }\end{array}$ & $\begin{array}{l}\text { Problematizar o uso do } \\
\text { tempo e do espaço no } \\
\text { currículo escolar em } \\
\text { uma escola de tempo } \\
\text { integral na cidade de } \\
\text { Santo ngelo. }\end{array}$ \\
\hline FIGUEIRED0, 2011 & $\begin{array}{l}\text { O projeto escola de } \\
\text { tempointegral:currículo } \\
\text { e práticas. Análise } \\
\text { de seus desafios e } \\
\text { possibilidades }\end{array}$ & $\begin{array}{l}\text { Discutir o currículo } \\
\text { e práticas a } \\
\text { partir da análise das } \\
\text { concepções, desafios } \\
\text { e possibilidades do } \\
\text { projeto de tempo } \\
\text { integral e refletir sobre a } \\
\text { relação existente entre } \\
\text { projeto e a melhoria } \\
\text { das aprendizagens dos } \\
\text { alunos. }\end{array}$ \\
\hline
\end{tabular}




\begin{tabular}{|c|c|c|}
\hline FONTANA, 2013 & $\begin{array}{l}\text { Escola de tempo } \\
\text { integral ou escola fora } \\
\text { do tempo escolar: o } \\
\text { caso de Barretos }\end{array}$ & $\begin{array}{l}\text { Analisara construção do } \\
\text { currículo da escola de } \\
\text { tempo integral em um } \\
\text { contexto educacional } \\
\text { formado pela parceria } \\
\text { entre duas instituições: } \\
\text { uma escola de ensino } \\
\text { fundamental e um } \\
\text { centro social urbano. }\end{array}$ \\
\hline HENRIQUES, 2012 & $\begin{array}{l}\text { A implementação da } \\
\text { política de educação } \\
\text { integral em tempo } \\
\text { integral na Escola } \\
\text { Municipal José } \\
\text { Ahouagi }\end{array}$ & $\begin{array}{l}\text { Analisar } \\
\text { i m p l e m e n t a çã o } \\
\text { da política pública } \\
\text { educacional, intitulada } \\
\text { como Programa de } \\
\text { Escola de Educação } \\
\text { em Tempo Integral, } \\
\text { na referida escola, } \\
\text { localizada no município } \\
\text { de Juiz de Fora. }\end{array}$ \\
\hline MOREIRA, 2013 & $\begin{array}{l}\text { Programa Mais } \\
\text { Educação: uma análise } \\
\text { de sua relação com o } \\
\text { currículo formal em três } \\
\text { escolas de Esteio - RS }\end{array}$ & $\begin{array}{l}\text { Analisar as relações } \\
\text { estabelecidas } \\
\text { o Programa } \\
\text { Educação e o currículo } \\
\text { formal escolar. }\end{array}$ \\
\hline RAMOS, 2011 & $\begin{array}{l}\text { Escola pública } \\
\text { integrada: uma } \\
\text { proposta sob análise }\end{array}$ & $\begin{array}{l}\text { Analisar o currículo } \\
\text { o b s e } r \text { v a } n \text { d o } \\
\text { especialmente os } \\
\text { aspectos relacionados } \\
\text { ao tempo, espaço e } \\
\text { matriz curricular de três } \\
\text { escolas com o intuito de } \\
\text { analisar a experiência } \\
\text { da Escola Pública } \\
\text { Integrada de Santa } \\
\text { Catarina. }\end{array}$ \\
\hline
\end{tabular}




\begin{tabular}{|l|l|l|l|}
\hline SILVA, 2011 & $\begin{array}{l}\text { Escola de Tempo } \\
\text { Integral: uma análise } \\
\text { da implantação na na trajetória da } \\
\text { Rede Estadual de Goiás } \\
(2006-2010)\end{array}$ & $\begin{array}{l}\text { Descrever e analisar } \\
\text { implantação da escola } \\
\text { de tempo integral da } \\
\text { Rede Estadual de Goiás. }\end{array}$ \\
\hline SOARES, 2014 & $\begin{array}{l}\text { A experiência das } \\
\text { escolas de tempo } \\
\text { integral de Apucarana - }\end{array}$ & $\begin{array}{l}\text { Analisar a implantação } \\
\text { do projeto de escolas } \\
\text { em tempo integral em } \\
\text { PR: sujeitos, marketing } \\
\text { político e currículo } \\
\text { Apucarana. }\end{array}$ \\
\hline
\end{tabular}

Fonte: Elaborado pelo autor com base no BDTD e no Banco de Teses da Capes.

As pesquisas identificadas diferem em vários aspectos, pois retratam experiências desenvolvidas em alguns estados e municípios sob diferentes ângulos, conforme os objetivos e metodologias propostos pelos seus pesquisadores. As escolas analisadas diferem na oferta da ampliação da jornada, sendo que, em algumas escolas, todos os alunos são matriculados obrigatoriamente no tempo integral e, em outras, apenas parte dos estudantes tem a jornada ampliada.

Ao analisá-las, optamos pela aproximação daquelas que mergulharam na realidade das escolas a fim de revelar como elas desenvolvem os programas de tempo integral e quais dificuldades enfrentam. As pesquisas focalizadas podem trazer importantes contribuições para os rumos da ETI porque apresentam como o seu programa está se efetivando no “chão da escola", e têm o potencial de revelar o currículo real. A cultura contida nos currículos já formulados ou planejados para a escola sofre outra série de modificações quando se desenvolve num meio escolar concreto (SACRISTÁN, 1998). Esse autor ainda afirma que "para entender o currículo real é preciso esclarecer os âmbitos práticos em que é elaborado e desenvolvido, pois, do contrário estaríamos falando de um objeto reificado à margem da realidade" (SACRISTÁN, 1998, p. 129). A seguir serão apresentadas sínteses das oito pesquisas selecionadas, na tentativa de compreender o currículo real da ETI.

Ramos (2011) analisou a configuração dos currículos de três escolas de tempo integral em Joinville, pertencentes à rede estadual de Santa Catarina. A proposta de escola pública integrada dessa rede é desenvolvida desde 2003, com a finalidade de ampliar as oportunidades de aprendizagem com uma jornada de nove horas para todos os alunos das séries iniciais do 
ensino fundamental, tendo um currículo que abrange as disciplinas da base comum, acrescidas de disciplinas diversificadas. Nessa proposta, o currículo da escola de tempo integral é único, devendo estruturar o próprio projeto político-pedagógico; os dados da pesquisa demonstraram que a matriz curricular e os tempos escolares são rígidos e controlados, dificultando o desenvolvimento de atividades diferenciadas. Em 2010, Santa Catarina possuía 68 escolas públicas integradas, atendendo um total de 8.005 alunos do ensino fundamental. Os índices alcançados pelas escolas pesquisadas na avaliação do Índice de Desenvolvimento da Educação Básica (Ideb) não foram melhores do que os índices das escolas com jornada reduzida, fato que causou estranheza. A autora conclui que o projeto não trouxe mudanças significativas na forma de organização dos currículos, tendo como diferencial apenas a quantidade de horas que os alunos permaneciam no interior das escolas. Os alunos permaneciam dentro das escolas durante toda a jornada em espaços inadequados e não houve investimentos por parte do poder público para que as escolas pudessem adequar suas estruturas físicas. Também não houve investimento na formação de professores para atuarem em tempo integral. Segundo a autora, a proposta carece de uma avaliação mais minuciosa e que contemple outros aspectos, pois na sua configuração atual mostra-se ineficaz.

Brandão (2009), ao problematizar o uso do tempo-espaço no currículo em uma escola estadual de tempo integral na cidade de Santo Ângelo (RS), concluiu que embora a escola de tempo integral utilize novas estratégias, mantém o propósito de disciplinar os indivíduos e produz modos de ser sujeitos adaptáveis e úteis ao seu tempo histórico. A escola pesquisada é um Ciep que oferece a ETI para todos os alunos, com a base comum no turno regulare oficinas, que são escolhidas pelos próprios alunos, no contraturno. A autora desenvolveu a pesquisa mediante análise de fotografias selecionadas pelos professores e funcionários da escola, acompanhadas de pequenos textos que justificavam a sua escolha. A análise foi realizada sob a perspectiva dos estudos culturais. Segundo a autora, o currículo aparece nas imagens e nos quadros de horário de forma disciplinar e flexível, acionando estratégias do uso do tempo e do espaço de forma atrativa. Contudo, a escola não deixa de exercer sua tarefa de disciplinar indivíduos e, no caso do tempo integral, as crianças ficam mais tempo aprisionadas pela "pedagogização" escolar. Apesar disso, a autora afirma que a escola continua representando a ideia de um futuro melhor para os sujeitos e de uma sociedade melhor e mais justa.

Moreira (2013) pesquisou três escolas na cidade de Esteio (RS), que ofereciam 
a jornada em tempo integral para parte de seus alunos, a fim de analisar as relações estabelecidas entre o PME e o currículo formal. A Secretaria Municipal de Educação de Esteio foi contemplada com o PME em 2009; sua implantação foi muito ágil e propiciada pelo contexto político. Inicialmente o programa foi implantado em 11 dos 18 Centros Municipais de Educação Básica (CMEB) e em 2011, ampliado para a sua totalidade. Em 2012, 24,23\% dos alunos matriculados no ensino fundamental de Esteio estavam cadastrados no PME (em nível nacional, esse percentual não alcançava 10\%). Apesar da acelerada e ampla implantação do programa, o município de Esteio não tinha uma política de educação integral definida e organizada, e isso representou uma fragilidade. As escolas enfrentaram muitas dificuldades nesse período (2009-2011), principalmente relacionadas à falta de estrutura e de pessoas qualificadas. A ampliação da jornada se realizou por meio de atividades desenvolvidas por oficineiros no contraturno, que atuavam como voluntários e recebiam apenas uma ajuda de custo. A falta de clareza sobre a proposta de educação integral e os critérios utilizados para a seleção de alunos colaboraram para que o programa fosse entendido como um conjunto de atividades extraclasse para alunos carentes. Entretanto, esse quadro vem se modificando e o entendimento do programa está caminhando no sentido de identificá-lo como uma oportunidade para desenvolver habilidades e competências que podem servir como um meio para que os estudantes obtenham bons resultados escolares. A autora entende que o PME explicita o desejo de intervir na organização curricular da escola na perspectiva da educação integral, entretanto, os resultados de sua pesquisa indicam que não há integração entre o PME e o currículo da escola, resultando em duas escolas em um mesmo espaço físico, apesar do desejo e da necessidade de que elas se fundam em uma única proposta educacional. A autora identificou o receio de repensar as estruturas escolares no que diz respeito ao espaço e tempo escolar, pois, ao que tudo indica, a continuidade do PME permanece incerta. A conclusão do estudo é que a educação integral com currículo integrado ainda está para ser inventada no Brasil e que, para garantir a universalização da educação integral em forma de jornada ampliada, serão necessários recursos estáveis, além de uma proposta pedagógica adequada. Além disso, conclui que há falta de clareza quanto aos objetivos do programa; em cada escola ainda persistem entendimentos heterogêneos sobre as finalidades de sua ação pedagógica, oscilando do suprimento de carências dos alunos empobrecidos à oportunidade de desenvolver as inteligências múltiplas.

Figueiredo (2011) discutiu o currículo de uma escola de tempo integral da rede estadual de Minas Gerais, situada em Belo Horizonte, e suas relações 
com a melhoria das aprendizagens dos alunos. A autora percebeu uma construção dual do currículo, com uma organização para o tempo parcial e outra para o tempo integral, e identificou como desafio a elaboração de um currículo único que contemple uma educação integral em tempo integral. A escola desenvolvia experiências com o tempo integral desde 1998, por meio de um projeto criado pela própria instituição; em 2004 a Secretaria de Educação implantou o Projeto Aluno de Tempo Integral (Pati) e, em 2007, o programa sofreu transformações, passando a se chamar Projeto Escola de Tempo Integral (Proeti), com a publicação de uma cartilha em 2009 contendo a caracterização pretendida para as escolas de tempo integral. Em Minas Gerais, no ano da pesquisa, apenas quatro escolas estaduais funcionaram com o tempo integral para todos os seus alunos, sendo duas no interior do estado e duas em Belo Horizonte. As outras 1.756 escolas, incluindo a escola pesquisada, funcionam com apenas algumas turmas em horário integral.

O estudo foi realizado no ano de 2010 e analisou documentos que registraram a trajetória de 12 anos do tempo integral na escola, além de utilizar outros instrumentos, tais como observações, entrevistas e questionários. Segundo a autora, com o Proeti houve uma ruptura nos caminhos do programa, que passou a controlar o desempenho dos alunos, principalmente em relação às proficiências em Língua Portuguesa e Matemática, deixando de lado as questões relacionadas ao acolhimento e proteção, como vinha acontecendo nas experiências anteriores da escola pesquisada. 0 foco passou a ser 0 resultado e não mais o processo, de acordo com o depoimento da diretora da escola. Por meio das entrevistas realizadas, comprovou-se uma desarticulação tanto entre o trabalho desenvolvido nos dois turnos, quanto entre o corpo docente. Dessa forma, em certos aspectos, o Proeti era visto como um sistema paralelo ao das turmas do tempo parcial da escola. A matriz curricular sugerida pelo Proeti em 2010 foi composta por oficinas de linguagem, matemática, formação pessoal e social, artística, recreação, balé e cozinha experimental. Apesar de figurar como sugestão, o que se observou é que a prática tinha seu cumprimento intensamente controlado e cobrado. A autora acredita que implantar a mesma matriz curricular sugerida às 1.981 escolas participantes do Projeto silencia as vozes de alguns alunos e dos professores. Admite também que a estandardização do currículo é um desafio a ser superado, mas, no caso de atribuir à escola a responsabilidade de organizar o currículo, é necessário investimento no sentido de promover estudos/cursos, com reflexões sobre as questões de transmissão, apropriação e legitimação dos conhecimentos escolares, algo que deve ser feito no longo prazo e sem aligeiramentos. A autora aponta algumas possibilidades para aprimorar o programa, tais como a 
implantação de um turno único para professores e alunos, a fim de minimizar a fragmentação do trabalho entre turno parcial e Proeti; também sugere uma diversificação no uso de espaços, tipos de atividades e diferentes educadores a fim de não tornar a jornada de nove horas cansativa para o aluno.

Henriques (2012) analisou a implementação do Programa Escola de Educação em Tempo Integral numa escola municipal de Juiz de Fora (MG) e constatou a necessidade de melhor organização interna e de maior parceria com a Secretaria de Educação, no intuito de fortalecer essa política pública. 0 programa foi implantado na Rede Municipal de Ensino de Juiz de Fora em 2006, mas somente em 2008 os textos legais referentes a essa política foram produzidos, o que revela certa precipitação na sua implantação. A autora observou que na escola a opção pelo tempo integral foi resultado mais de um processo administrativo que de uma discussão democrática com a comunidade escolar, envolvendo barganha entre interesses políticos da administração municipal e necessidades da escola. Ela já desenvolvia alguns projetos optativos para os alunos, mas, quando o tempo integral passou a ser obrigatório para todos os alunos da escola, foi necessário rever seu projeto político-pedagógico. Os alunos passaram a ter uma jornada escolar de nove horas, reduzida posteriormente para oito horas, devido ao cansaço observado nos discentes. A organização curricular também passou por mudanças ao longo da implementação do programa, por causa das dificuldades enfrentadas. Dentre as dificuldades, destacam-se: a) obrigatoriedade do tempo integral para todos, pois muitos alunos dos anos finais do ensino fundamental não se interessavam pelos projetos do tempo integral; b) organização curricular fragmentada, pois no turno da manhã concentravamse as disciplinas do núcleo comum e no período da tarde eram desenvolvidos os projetos; e c) impossibilidade de os alunos escolherem os projetos de que desejavam participar. Além dos problemas identificados, os dados da pesquisa evidenciaram ineficiência e descontinuidade na implementação da política pública, acentuada pela troca da gestão de governo.

Fontana (2013) representa a única tese de doutorado no resultado da busca e também a única pesquisa realizada no estado de São Paulo (Barretos). A autora analisou a construção do currículo da escola de tempo integral em um contexto educacional formado pela parceria entre duas instituições: uma escola de ensino fundamental e um centro social urbano (CSU). As escolas de tempo integral em Barretos iniciaram suas experiências em 2006 e as dificuldades enfrentadas revelaram que, apesar de a proposta ter sido preparada e gestada no ano anterior com propósitos bem-intencionados e 
democráticos, inclusive com a criação de um centro de formação de professores e coordenadores para atuarem no projeto, a preocupação com a inauguração das escolas e equipamentos sobrepujava a questão educacional e as decisões passaram a ser tomadas unilateralmente, evidenciando interesses políticos e eleitorais. Ao longo da implantação do programa, as improvisações e a falta de conceituação sobre o que de fato significa a extensão do tempo escolar se intensificaram. Em 2010, um CSU passou a atender os alunos do projeto e foi selecionado como objeto de estudo da pesquisa. Apesar de não ser um centro educativo formal, o CSU passou a atender de forma improvisada parte dos alunos de uma escola no contraturno. Na teoria, o objetivo do programa de Barretos é ocupar de forma positiva o tempo das crianças com aprendizagens significativas, por meio de atividades pedagógicas, esportivas, recreativas, sociais e semiprofissionalizantes, que incorporam uma ampliação no número de horas em que a criança ou o adolescente permanecem na instituição escolar. No entanto, os resultados indicaram que esse objetivo está distante de ser alcançado na prática. Os docentes e o diretor da escola apontaram mais aspectos negativos do que positivos no programa e relataram não notarem diferenças entre os alunos que frequentam o período integral e o parcial, inclusive em relação ao desempenho acadêmico. Os resultados também apontaram os escassos equipamentos e recursos pedagógicos, além de insuficientes espaços para descanso e lazer dos alunos. A autora caracterizou o CSU de Barretos como um local de educação não formal que se distancia do objetivo da escola de tempo integral, embora ela reconheça a importância da educação não formal para a formação das crianças e adolescentes.

Complementando a análise, registramos de forma breve dois estudos sobre redes de ensino. Soares (2014) analisou a implementação da escola de tempo integral no município de Apucarana (PR) ao longo de sua primeira década, mediante a prescrição do currículo e dos discursos. Em Apucarana, as escolas municipais que são de tempo integral oferecem a jornada ampliada para todos os alunos matriculados. 0 autor percebeu contradições e o uso desse projeto como marketing político; sugere que estudos futuros investiguem como esse currículo acontece na prática e como os sujeitos dele se apropriam.

Silva (2011) descreveu e analisou a trajetória de implantação da escola de tempo integral na rede estadual de Goiás por meio de pesquisa documental bibliográfica. 0 projeto de Goiás atendia prioritariamente os alunos das séries iniciais do ensino fundamental, com a totalidade desses alunos matriculados no tempo integral. Constatou que o processo de implantação deu-se de forma tumultuada e improvisada, e concluiu que o projeto teve intenções eleitorais. 
A autora aponta a necessidade de estudos futuros no "chão da escola" que possam focalizar a implementação na perspectiva da escola e de seus sujeitos.

\section{ANÁLISE dOS PROBLEMAS DA ETI INDICADOS PELA PRODUÇÃO ACADÊMICA}

Com exceção do estudo de Brandão (2009), todas as pesquisas constataram falta de investimentos adequados para o funcionamento da escola de tempo integral, seja na estrutura física ou na contratação e formação de recursos humanos. Isso pode estar associado aos interesses políticos eleitorais identificados nas pesquisas, tanto nas ações precipitadas para inaugurar tais políticas quanto nas descontinuidades dos programas observadas nas trocas de gestões de governo. Esses problemas se intensificam na ETI, pois no modelo são necessárias mudanças na organização escolar que nem sempre são bancadas pelos seus atores, seja pelo temor de que elas não se mantenham, seja por eles desconfiarem dos reais interesses desses programas. As dúvidas em relação à continuidade dos programas de ETI são justificáveis, haja vista a descontinuidade de programas como os Cieps e o Profic. Como observa Guará (2006), a descontinuidade desses programas é indicativa das dificuldades de implantação e até mesmo de aceitação dessas propostas, que não se mostraram sustentáveis em longo prazo, não atingiram os padrões de qualidade esperados e levantaram questionamentos em relação à demanda de proteção social em contraponto à função da escola.

Diante desse quadro, questiona-se a validade da ampliação do tempo integral. Essa dúvida já foi levantada por Paro et al. (1988):

Diante dessa situação em que se encontra a escola pública, e tendo em vista a prioridade da aplicação de recursos, pergunta-se: aplicam-se os recursos para melhorar as condições de aprendizagem dentro da escola, pelo menos em meio período, ou aplicam-se os recursos para estender a escolaridade diária para tempo integral, multiplicando por dois a calamidade aí presente? (PARO et al., 1988, p. 224).

A meta 6.2 do PNE 2014-2024 refere-se à infraestrutura; sua estratégia é institucionalizar e manter, em regime de colaboração, um programa nacional de ampliação e reestruturação das escolas públicas. Em 2013, apenas 3\% das escolas de tempo integral possuíam infraestrutura adequada (TODOS PELA EDUCAÇÃO, 2015). Problemas de infraestrutura não são exclusivos da ETI, eles estão presentes também nas escolas de tempo parcial, assim como aqueles relativos ao currículo, à formação de professores, entre outros. Ampliar a jornada do aluno sem levar em consideração os graves problemas encontrados nas escolas de tempo parcial pode levar a uma ampliação desses 
problemas e não contribuir para a melhoria da aprendizagem. Os estudos de Ramos (2011) e de Fontana (2013), por exemplo, relataram que não houve melhoria da aprendizagem entre os alunos matriculados na ETI, e os demais estudos analisados não revelaram avanços nesse sentido. Cavaliere (2006) afirma que um tempo de escola organizado de forma convencional e meramente duplicado em horas é desnecessário e ineficaz. A proposta de ampliação do tempo diário de escola só faz sentido se trouxer uma reorganização inteligente desse tempo e se levar em conta as peculiaridades presentes em cada escola.

Galian e Sampaio (2012), ao analisarem as propostas de ETI e propostas curriculares de diferentes estados e municípios brasileiros, constataram que, ao ampliar o tempo de permanência de crianças e jovens na escola, a tendência é de manter as práticas tradicionais e acrescentar outras atividades em horários complementares, sem que se discuta o que se espera como resultado do processo de escolarização nesses novos moldes. Essas autoras também apresentaram os questionamentos de Menezes (2009) sobre as intenções por trás da ampliação da jornada escolar e acrescentam que manter as crianças longe das ruas enquanto seus pais trabalham parece ser uma preocupação da educação integral:

Muito provavelmente uma preocupação maior com a garantia das necessidades práticas do mundo do trabalho ou até para assegurar tranquilidade às pessoas nos espaços públicos, do que o cuidado com aquelas questões que respondem a uma formação integral das crianças e jovens nas escolas (GALIAN; SAMPAIO, 2012, p. 407).

Os documentos que estruturam a política para a ETI apontam benefícios para os alunos, mas seria pertinente admitir outros interesses por trás dessa política? Cavaliere (2006) questiona as motivações da ampliação da jornada escolar e levanta dúvidas, ao afirmar:

Do ponto de vista político, as definições do tempo escolar podem sempre ser relacionadas a expectativas ou projetos de governo e de sociedade. Em geral, a motivação para as mudanças do tempo de escola embute questões ideológicas, ainda que encobertas por demandas de caráter pragmático (CAVALIERE, 2006, p. 94).

Do ponto de vista econômico ou produtivista, a escolarização pode ser interpretada como a forma de participação das crianças na divisão social do trabalho, como forma de agregar valor ao capital humano (QVORTRUP, 2014, 2015). Desse modo, ao ampliar a jornada dos alunos sem questionar as finalidades dessa política, a ETI pode se reduzir a uma forma produtivista de controle externo do tempo da criança, preparando-a para ocupar funções 
em jornada de tempo integral, ao mesmo tempo que possibilita aos pais se dedicarem integralmente ao trabalho.

Talvez a ETI esteja se distanciando da função das instituições escolares, que, de acordo com Forquin (1993), se relaciona com o fato de serem, por destinação, lugares de transmissão e de aquisição de conhecimentos, de capacidades e de hábitos. Retirar as crianças das ruas e garantir um lugar para os pais deixarem seus filhos enquanto trabalham são justificativas para a implantação do tempo integral presentes em muitos discursos durante as campanhas eleitorais, embora as diretrizes do PME e do PNE apresentem finalidades diferentes. Giolo (2012) defende que a escola de tempo integral não deve perder de vista que o grande desafio da educação básica é fazer com que os alunos aprendam os conteúdos previstos em sua matriz curricular, sendo esta a razão principal a exigir a ampliação do tempo escolar. Entretanto, a ideia do acolhimento ainda está presente nos programas de escolas de tempo integral de muitos municípios e essa ideia, aparentemente ética, pode ser perversa, como ressalta Libâneo (2012) em artigo que revela a dualidade da escola pública brasileira, distinguindo a escola do conhecimento para os ricos e a escola do acolhimento social para os pobres.

Todas as crianças e jovens necessitam de uma base comum de conhecimentos, junto a ações que contenham o insucesso e o fracasso escolar. É claro que a escola pode, por um imperativo social e ético, cumprir algumas missões sociais e assistenciais (a escola convive com pobreza, fome, maus-tratos, consumo de drogas, violência etc.), mas isso não pode ser visto como sua tarefa e sua função primordiais, mesmo porque a sociedade também precisa fazer sua parte nessas missões sociais e assistenciais (LIB NEO, 2012, p. 26).

Existe o risco de que a escola de tempo integral possa escorregar para uma proposta de completude, tornando-se o que Foucault denunciou como instituição total (FOUCAULT, 1993 apud GUARÁ, 2006). Prover, num único espaço, atividades que atendam a todas as necessidades da criança tende a carregar para esse ambiente a disciplinarização e a limitação de contatos e alternativas (GUARÁ, 2006).

\footnotetext{
A submissão dos alunos a práticas espaço-temporais de contenção e massificação, na perspectiva da disciplinarização como estratégia educativa, tem produzido poucos resultados em termos de motivação e interesse pela aprendizagem (GUARÁ, 2006, p. 22).
}

Atentos aos riscos de as escolas de tempo integral se tornarem lugares de contenção e massificação, alguns municípios valorizam o potencial educativo das mais diversas instituições da comunidade e incorporam em seus programas de ETI a utilização de outros espaços educativos para além dos 
muros da escola, apropriando-se da cidade como grande espaço educador e alinhando-se aos princípios contidos na Carta das Cidades Educadoras ${ }^{4}$. Entretanto, a tentativa de apropriação de outros espaços da cidade, evocando o conceito de Cidade Educadora nos programas de ETI, é questionável diante dos relatos de problemas associados à falta de infraestrutura das escolas. Pode ser uma forma de driblar a necessidade de construção e ampliação dos prédios escolares, que continuam funcionando em dois turnos, além de comportar as atividades dos alunos matriculados em tempo integral. Cavaliere (2014) alerta para a apropriação indevida do conceito de Cidade Educadora no contexto brasileiro. Para a autora, a proposta da Cidade Educadora é

[...] inovadora e interessante, fruto de determinadas realidades sociais, urbanas e educacionais. No Brasil, sua justificativa, diferentemente daquela do movimento original europeu, é com frequência uma função da ausência de infraestrutura e espaço nos prédios escolares para a ampliação do tempo escolar, tendo sido chamada de "tecnologia educacional de baixo custo" [...] (CAVALIERE, 2014, p. 1217).

Uma das pesquisas analisadas constatou que muitos alunos dos anos finais do ensino fundamental (EF) não se interessavam pelos projetos do tempo integral e que as dificuldades na implantação se associavam principalmente a esse segmento (HENRIQUES, 2012). Fato semelhante foi observado nos Cieps, onde poucas unidades dos anos finais do EF e do ensino médio permaneceram funcionando em tempo integral, enquanto as unidades de educação infantil e séries iniciais do $E F$, apesar de terem enfrentado inúmeras dificuldades, contabilizam já cerca de 20 anos de funcionamento com jornada integral. Nos países europeus, as crianças menores ficam menos tempo na escola, e esse tempo vai sendo progressivamente ampliado para as crianças maiores e para os adolescentes. Entretanto, no Brasil, são as crianças menores que permanecem mais tempo na escola (CAVALIERE, 2006). Segundo dados do Observatório do PNE, em 2014 as matrículas nas escolas públicas de tempo integral brasileiras atingiram apenas $5,7 \%$ dos alunos do ensino médio. Por outro lado, nos anos iniciais do EF, esse número chegou a 20,5\% e, nas creches, a 63,7\% (TODOS PELA EDUCAÇÃO, 2015). Esses dados apontam para a atualidade da afirmação de Cavaliere:

Esse é um forte indício de que são as necessidades prementes dos pais em ter seus filhos menores protegidos enquanto trabalham o principal motor da adesão à escola de tempo integral. Nesse caso, são os interesses e necessidades da vida adulta exercendo seu papel no processo de definição do tempo de escola das crianças (CAVALIERE, 2006, p. 96).

A Carta das Cidades Educadoras surgiu em 1990, no I Congresso Internacional de Cidades Educadoras, em Barcelona, em que um grupo de cidades pactuou o objetivo comum de trabalharem juntas em projetos e atividades para melhorar a qualidade de vida dos habitantes. Para mais informações, acessar: «http://www.cidadeseducadorasbrasil.net. br/Cidade-Educadora.aspx>. 
Há programas que tentam romper com a ideia de oferecer mais do mesmo aos alunos e buscam uma educação integral em tempo integral. Tais propostas contemplam outros saberes que até então não tinham muito espaço no currículo formal, com oficinas de arte, música, esporte e que também valorizam a cultura local e comunitária. Muitos programas optam pela contratação de oficineiros, estagiários e agentes culturais da comunidade, em condições precárias relativas ao vínculo de trabalho, gerando elevada rotatividade desses agentes, especialmente nos grandes centros, o que agrava ainda mais as dificuldades de integração das atividades por eles conduzidas com as atividades da escola (CAVALIERE, 2014). Esse modelo tem reforçado a ideia equivocada de que a escola de tempo integral é o somatório de um turno regular, em que todos os alunos estudam a base comum, e um contraturno em que os alunos carentes têm um conjunto de atividades extraclasse de menor importância, sem que exista qualquer comunicação entre as duas propostas, embora ambas coexistam na mesma escola.

A escola de tempo integral requer um currículo único para um turno integral; essa dualidade na construção do currículo apresentou-se como um problema, evidenciado nos estudos de Moreira (2013), Figueiredo (2011), Henriques (2012) e Fontana (2013). Cavaliere (2014) faz um alerta para os riscos desse modelo.

A ampliação da jornada escolar pela anexação de um turno adicional ou um "contraturno", entendido como "complementar", fundamentalmente distinto do tempo regular e destinado a apenas alguns alunos, pode ser um passo em falso na busca da melhoria da qualidade da educação brasileira (CAVALIERE, 2014, p. 1212).

Além disso, desde sua origem em 2007, o PME estabelece que as atividades desenvolvidas na ampliação da jornada devem ser integradas ao projeto político-pedagógico das redes de ensino e escolas participantes (BRASIL, 2007). Essa ideia é reforçada em 2010, nas Diretrizes Curriculares para o Ensino Fundamental de nove anos, ao afirmar que as atividades devem ser articuladas aos componentes curriculares e às áreas de conhecimento, sempre de acordo com o projeto político-pedagógico da escola (BRASIL, 2010).

O PME apresenta pressupostos para que as redes e escolas elaborem suas propostas de educação em tempo integral. Entretanto, Gabriel e Cavaliere (2012) questionam a capacidade de o currículo prescrito pelo PME romper com a desigualdade social perpetuada pela escola. Segundo essas autoras, quando referida à educação escolar, a educação integral apresenta o sentido de religação entre a ação intencional da instituição escolar e a vida em sentido amplo, porém, elas alertam para os riscos do movimento de integração "para 
além da escola”, que, apesar de trazer elementos novos para a escola, pode se confundir com um esvaziamento do lugar específico que essa instituição assume na luta hegemônica pela democratização da educação básica.

Young (2007) ressalta que o objetivo da escola é transmitir o "conhecimento poderoso", aquele que pode fornecer explicações confiáveis ou novas formas de se pensar a respeito do mundo, diferenciando-o do "conhecimento dos poderosos", que é definido por quem detém o conhecimento. Esse autor afirma que "não há nenhuma utilidade para os alunos em se construir um currículo em torno da sua experiência, para que este currículo possa ser validado e, como resultado, deixá-los sempre na mesma condição" (YOUNG, 2007, p. 1297). Assim sendo, defende a ideia de diferenciação do conhecimento, baseada na distinção entre conhecimento escolar e não escolar. Young não rejeita o princípio de que o currículo tem que levar em consideração o conhecimento local e cotidiano que os alunos trazem para a escola, mas entende que esse conhecimento local e cotidiano nunca poderá ser uma base para o currículo.

\section{CONSIDERAÇÕES FINAIS}

As pesquisas revelam que o contexto da realização está distante do contexto da formulação, no que se refere às finalidades da ETI presentes nos documentos oficiais. Ainda não há uma visão clara sobre o currículo da escola de tempo integral e essa política está sendo implementada de forma precipitada e com recursos insuficientes. Num ambiente de desconfianças, incertezas, improvisos e falta de condições adequadas, as escolas, pressionadas por interesses eleitorais, são obrigadas a implantar o tempo integral sem que haja diálogo e orientação. Nos contextos pesquisados, as experiências são heterogêneas e os avanços quase sempre insuficientes para atender à meta prevista no PNE. Entretanto, há propostas que estão sendo implantadas com mais sucesso em outras escolas ou redes e que são descritas em alguns livros e publicações. Diante de resultados antagônicos encontrados nas pesquisas de pós-graduação, comparados com as experiências descritas em outras publicações ${ }^{5}$, são necessários estudos mais abrangentes para avaliar a implantação da ETI no Brasil e apontar rumos mais confiáveis para essa política.

Para saber mais sobre essas experiências, consultar: MOLL, Jaqueline et al. Caminhos da educação integral no Brasil. Porto Alegre: Penso, 2012. 


\section{Full-Time Education: Contributions from Graduate Studies}

Abstract: This article aims to present an overview of graduate studies on fulltime education (FTE) and its curriculum. Our analysis of eight studies selected from the data base Banco de Teses da Capes and of Biblioteca Digital Brasileira de Teses showed that: a) the realization context is far from the formulation context, considering what official documents set forth as goals of FTE; b) FTE implementation presented problems, some of which appear in various schools and regions; $c$ ) there is still no clear conception about the curriculum of the full-time school.

Keywords: Education. Full-time. Curriculum. National Education Plan. 


\section{Educación a tiempo completo: contribuciones procedentes de las investigaciones de posgrado}

Resumen: La propuesta de este artículo es presentar el panorama de las investigaciones procedentes del posgrado stricto sensu que tratan sobre la educación a tiempo completo (ETC) y su currículo. El análisis de ocho investigaciones seleccionadas en la base de datos del Banco de Tesis de la Capes y de la Biblioteca Digital Brasileña de Tesis y Disertaciones reveló: a) que el contexto de la realización está lejos del contexto de la formulación, en lo que se refiere a las finalidades de la ETC presentes en los documentos oficiales; b) que la implantación presentó problemas que hay que superar, algunos de los cuales se repiten en diferentes lugares; y c) que aún no existe una visión clara sobre el currículo de la escuela de tiempo completo.

Palabras clave: Educación. Tiempo completo. Currículo. Plan Nacional de Educación. 


\section{REFERÊNCIAS}

BELO HORIZONTE. Secretaria Municipal de Educação. Coordenação do Programa Escola Integrada. Escola integrada: novos tempos, lugares e modos para aprender, Belo Horizonte, 2008.

BRANDÃO, Arlita Rodrigues. Tempo e espaço no currículo escolar. 2009. 111 f. Dissertação (Mestrado em Educação)-Programa de Pós-Graduação em Educação, Universidade do Vale do Rio do Sinos, São Leopoldo, 2009.

BRASIL. Lei n. 9.394, de 20 de dezembro de 1996. Estabelece as diretrizes e bases da educação nacional. Diário Oficial da União, Brasília, DF, 23 dez. 1996.

Portaria Normativa Interministerial n. 17, de 24 de abril de 2007. Institui o Programa Mais Educação. Diário Oficial da União, Brasília, DF, 26 abr. 2007a.

. Lei n. 11.494, de 2007. Regulamenta o Fundeb. Diário Oficial da União, DF, 21 jun. 2007b.

- Ministério da Educação. Rede de saberes mais educação: pressupostos para projetos pedagógicos de educação integral. Caderno para professores e diretores de escolas. 1. ed. Brasília, 2009.

. Decreto presidencial no 7.083 de 2010. Dispõe sobre o Programa Mais Educação. Diário Oficial da União, Brasília, DF, 27 jan. 2010a.

- Ministério da Educação. Conselho Nacional de Educação. Câmara de Educação Básica. Resolução № 7 de 2010. Fixa Diretrizes Curriculares Nacionais para o Ensino Fundamental de 9 (nove) anos. Brasília, 2010 b.

Lei n. 13.005, de 25 de junho de 2014. Aprova o Plano Nacional de Educação (2014-2024). Diário Oficial da União, Brasília, DF, 26 jun. 2014.

CAVALIERE, Ana Maria. Em busca do tempo de aprender. Cadernos Cenpec, v. 1, n. 2, p. 91-101, 2006.

. Escola pública de tempo integral no Brasil: filantropia ou política de estado? Educação \& Sociedade, Campinas, v. 35, n. 129, p. 1205-1222, out./ dez. 2014.

FIGUEIREDO, Verônica Cristina de Almeida e Silva de Barros. 0 projeto 
escola em tempo integral: currículo e práticas. Análise de seus desafios e possibilidades. 2011. 147 f. Dissertação (Mestrado em Educação)-Programa de Pós-Graduação em Educação, Pontifícia Universidade Católica de Minas Gerais, Belo Horizonte, 2011.

FONTANA, Silene. Escola de tempo integral ou escola fora do tempo escolar: o caso de Barretos. 2013. 160 f. Tese (Doutorado em Educação)-Programa de Pós-Graduação em Educação, Pontifícia Universidade Católica de São Paulo, São Paulo, 2013.

FORQUIN, Jean Claude. Escola e cultura. Bases sociais e epistemológicas do conhecimento escolar. Porto Alegre: Artmed, 1993.

FOUCAULT, Michel. Vigiar e punir: nascimento da prisão. Trad. Lígia M. Pondé Vassallo. Petrópolis: Vozes, 1993 apud GUARÁ, Isa Maria F. Rosa. É imprescindivel educar integralmente. Cadernos Cenpec, v. 1, n. 2, p. 15-24, 2006.

GABRIEL, Carmen Teresa; CAVALIERE, Ana Maria. Educação integral e currículo integrado: quando dois conceitos se articulam em um programa. In: MOLL, Jaqueline et al. Caminhos da educação integral no Brasil: direitos a outros tempos e espaços educativos. Porto Alegre: Penso, 2012.

GALIAN, Cláudia Valentina Assumpção; SAMPAIO, Maria das Mercês Ferreira. Educação em tempo integral: implicações para o currículo da escola básica. Currículo sem Fronteiras, v. 12, n. 2, p. 403-422, maio/ago. 2012.

GIOLO, Jaime. Educação de tempo integral: resgatando elementos históricos e conceituais para o debate. In: MOLL, Jaqueline et al. Caminhos da educação integral no Brasil: direitos a outros tempos e espaços educativos. Porto Alegre: Penso, 2012.

GOMES, Cândido Alberto. Darcy Ribeiro. Recife: Fundação Joaquim Nabuco, Editora Massangana, 2010.

GUARÁ, Isa Maria F. Rosa. É imprescindível educar integralmente. Cadernos Cenpec, v. 1, n. 2, p. 15-24, 2006.

HENRIQUES, Anna Cristina. Perantoni. A implementação da política de educação integral em tempo integral na Escola Municipal José Calil Ahouagi. 2012. 92 f. Dissertação (Mestrado Profissional em Gestão e Avaliação da Educação Pública) - Programa de Pós-Graduação Profissional em Gestão e Avaliação da Educação Pública, Universidade Federal de Juiz de Fora, Juiz de 
Fora, 2012.

LIB NEO, José Carlos. 0 dualismo perverso da escola pública brasileira: escola do conhecimento para os ricos, escola do acolhimento social para os pobres. Educação e Pesquisa, São Paulo, v. 38, n. 1, p. 13-28, 2012.

MENEZES, Janaina Specht da Silva. Educação integral \& tempo integral na educação básica. In: COELHO, Lígia Martha Coimbra da Costa (Org.). Educação integral em tempo integral: estudos e experiências em processo. Petrópolis: Faperj, 2009.

. Educação em tempo integral: direito e financiamento. Educar em Revista, Curitiba, n. 45, p. 137-152, jul./set. 2012.

MOREIRA, Simone Costa. Programa Mais Educação: uma análise de sua relação com o currículo formal em três escolas de Esteio - RS. 2013. 170 f. Dissertação (Mestrado em Educação) Programa de Pós-Graduação em Educação, Universidade Federal do Rio Grande do Sul, Porto Alegre, 2013.

PARO, Vitor et al. Escola de tempo integral: desafio para o ensino público. São Paulo: Cortez, Autores Associados, 1988.

QVORTRUP, Jens. Visibilidades das crianças e da infância. Linhas Críticas, Brasília, v. 20, n. 41, p. 23-42, jan./abr. 2014.

. A dialética entre a proteção e a participação. Currículo sem Fronteiras, v. 15, n. 1, p. 11-30, jan./abr. 2015.

RAMOS, Ines Odorizzi. Escola pública integrada: uma proposta sob análise. 2011. 110 f. Dissertação (Mestrado em Educação)-Programa de PósGraduação em Educação, Universidade do Vale do Itajaí, Itajaí, 2011.

SACRISTÁN, José Gimeno. O currículo: os conteúdos do ensino ou uma análise prática? In: GÓMEZ, Angel Ignacio Pérez. Compreender e transformar o ensino. Porto Alegre: Artmed, 1998.

SILVA, Flávia Osório. Escola de tempo integral: uma análise da implantação na Rede Estadual de Goiás (2006-2010). 2011. 122 f. Dissertação (Mestrado em Educação) - Programa de Pós-Graduação em Educação, Universidade Federal de Goiás, Goiânia, 2011.

SOARES, Diego Fávero. A experiência das escolas de tempo integral de Apucarana - PR: sujeitos, marketing político e currículo prescrito. 2014.90 f. 
Dissertação (Mestrado em História Social)-Programa de Pós-Graduação em História Social, Universidade Estadual de Londrina, Londrina, 2014.

TODOS PELA EDUCAÇÃO. Observatório do PNE. Metas do PNE. Educação Integral. Disponível em: 〈http://www.observatoriodopne.org.br/metas-pne/6educacao-integral». Acesso em: 5 out. 2015.

YOUNG, Michael. Para que servem as escolas? Educação \& Sociedade, Campinas, v. 28, n. 101, p. 1287-1302, set./dez. 2007.

Sobre as autoras:

Elba Siqueira de Sá Barretto é pedagoga e doutora em Sociologia pela Universidade de São Paulo. Atua como professora do Programa de PósGraduação em Educação da Faculdade de Educação da Universidade de São Paulo (Feusp) e consultora da Fundação Carlos Chagas.

ebarretto@fcc.org.br

Katia Regina de Sá é mestre em Educação Física pela Universidade Federal de Minas Gerais (UFMG) e doutoranda na Feusp. Trabalha como professora do Instituto Federal de Minas Gerais - Campus Betim.

katia.sa@usp.br

Recebido em: abril de 2016

Aprovado em: agosto de 2016 